\title{
$B C R-A B L 1$ kinase domain mutations may persist at very low levels for many years and lead to subsequent TKI resistance
}

\author{
W T Parker ${ }^{1}$, A L Yeoman ${ }^{1}$, B A Jamison ${ }^{1}$, D T Yeung ${ }^{1,2}$, H S Scott ${ }^{1,2,3}$, T P Hughes ${ }^{2,4}$ and S Branford ${ }^{1,2,3}$ \\ ${ }^{1}$ Department of Molecular Pathology, Centre for Cancer Biology, SA Pathology, Adelaide, South Australia, Australia; ${ }^{2}$ School of \\ Medicine, University of Adelaide, Adelaide, South Australia, Australia; ${ }^{3}$ School of Molecular and Biomedical Science, University of \\ Adelaide, Adelaide, South Australia, Australia and ${ }^{4}$ Department of Haematology, Centre for Cancer Biology, SA Pathology, \\ Adelaide, South Australia, Australia
}

Background: BCR-ABL1 mutation analysis is recommended for chronic myeloid leukaemia patients. However, mutations may become undetectable after changing therapy, and it is unknown whether they have been eradicated.

Methods: We examined longitudinal data of patients with imatinib-resistant mutations, which became undetectable by Sanger sequencing to determine whether mutations could reappear, and the related circumstances.

Results: Identical imatinib- and nilotinib-resistant mutations reappeared following further therapy changes in five patients, and was associated with subsequent nilotinib resistance in four.

Conclusion: The data suggest that some BCR-ABL1 mutations may persist at undetectable levels for many years after changing therapy, and can be reselected and confer resistance to subsequent inhibitors.

Although the tyrosine kinase inhibitor (TKI) imatinib has revolutionised, the treatment of chronic myeloid leukaemia (CML) and most patients respond well, a significant minority acquire resistance. Mutations in the $B C R-A B L 1$ kinase domain are the best characterised cause. Although second-generation TKIs nilotinib and dasatinib were designed to target most imatinibresistant mutations, some also confer clinical resistance to either nilotinib or dasatinib or both (T315I; Soverini et al, 2011). Therefore, it is recommended that mutation analysis be performed at TKI failure to aid subsequent therapy selection (Soverini et al, 2011). Particular second-line TKIs are recommended when specific mutations are detected by conventional sequencing techniques (Soverini et al, 2011). For example, dasatinib is recommended for patients with $\mathrm{F} 359 \mathrm{~V}$ or $\mathrm{Y} 253 \mathrm{H}$, nilotinib for patients with F317L, and ponatinib for patients with T315I. Using sensitive mass spectrometry-based mutation analysis, we have shown that detection of low levels of these same mutations is also predictive of response and their rapid clonal expansion with inappropriate TKI therapy (Parker et al, 2011). Hence, the same precautions with TKI selection apply. Mutant BCR-ABL1 clones are often deselected upon TKI cessation or change of therapy, and may become undetectable, even by very sensitive techniques (Hanfstein et al, 2011; Gruber et al, 2012). In the absence of the selective pressure of TKI, BCR$A B L 1$ mutations appear to confer a proliferative disadvantage, allowing the unmutated clone to predominate (Hanfstein et al, 2011). It is not known whether treatment discontinuation or long-term alternative TKI therapy leads to eradication of these mutant clones. If mutant clones persist at undetectable levels they have the potential to be reselected and expand clonally, given favourable conditions, such as change to a TKI for which they confer resistance. We examined longitudinal data of patients with imatinib-resistant mutations that became undetectable by direct Sanger sequencing, to determine whether 'long dormant' mutations could reappear, and the circumstances related to their reappearance. 
Table 1. Details of patients with imatinib-resistant mutant BCR-ABL1 clones that became undetectable by Sanger-sequencing after changing therapy

\begin{tabular}{|c|c|c|c|c|c|c|c|c|}
\hline $\begin{array}{l}\text { Patient } \\
\text { ID }\end{array}$ & $\begin{array}{c}\text { Mutations } \\
\text { detected by } \\
\text { Sanger- } \\
\text { sequencing } \\
\text { during imatinib } \\
\text { therapy }\end{array}$ & $\begin{array}{c}\text { Circumstances } \\
\text { associated } \\
\text { with } \\
\text { disappearance } \\
\text { of mutations }\end{array}$ & $\begin{array}{l}\text { Time for } \\
\text { mutation } \\
\text { to } \\
\text { disappear } \\
\text { (months) }\end{array}$ & $\begin{array}{c}\text { Mutations } \\
\text { that } \\
\text { reappeared }\end{array}$ & $\begin{array}{c}\text { Circumstances } \\
\text { associated } \\
\text { with mutation } \\
\text { reappearance }\end{array}$ & $\begin{array}{c}\text { Time between mutation } \\
\text { disappearance and last } \\
\text { follow-up (patients 1-15) } \\
\text { or reappearance (patients } \\
\text { 16-20; years) }\end{array}$ & $\begin{array}{l}\text { Follow- } \\
\text { up since } \\
\text { starting } \\
\text { imatinib } \\
\text { (years) }\end{array}$ & $\begin{array}{l}\text { Disease } \\
\text { status at the } \\
\text { last follow- } \\
\text { up sample } \\
\text { received }\end{array}$ \\
\hline 1 & E255K & Chemotherapy & 1.9 & & & 0.1 & 0.6 & $\begin{array}{l}\text { Death due to } \\
\text { HSCT } \\
\text { complication }\end{array}$ \\
\hline 2 & G250E & Allogeneic HSCT & 1.4 & & & 0.2 & 1.8 & $\begin{array}{c}B C R-A B L 1 \\
\text { undetectable }\end{array}$ \\
\hline 3 & E255K & Allogeneic HSCT & 3.5 & & & 0.5 & 3.5 & $\begin{array}{c}\text { BCR-ABL1 } \\
\text { undetectable }\end{array}$ \\
\hline 4 & E459K & Allogeneic HSCT & 1.7 & & & 3.5 & 4.8 & $\begin{array}{c}\text { BCR-ABL1 } \\
\text { undetectable }\end{array}$ \\
\hline 5 & $\mathrm{Y} 253 \mathrm{H}$ & $\begin{array}{c}\text { Increased imatinib } \\
\text { dose }\end{array}$ & 7.8 & & & 3.9 & 8.1 & $\begin{array}{c}B C R-A B L 1 \\
\text { undetectable }\end{array}$ \\
\hline 6 & F317L, Y253H & $\begin{array}{c}\text { Increased imatinib } \\
\text { dose (F317L)/switch } \\
\text { to dasatinib } \\
\text { (Y253H) }\end{array}$ & $3.6,2.1$ & & & 0.5 & 2.1 & $\begin{array}{l}\text { Death due to } \\
\text { HSCT } \\
\text { complication }\end{array}$ \\
\hline 7 & E453G & $\begin{array}{c}\text { Increased imatinib } \\
\text { dose }\end{array}$ & 1.8 & & & 3 & 6.9 & $\begin{array}{c}\text { BCR-ABL1 } \\
\text { undetectable }\end{array}$ \\
\hline 8 & G250E & Switch to dasatinib & 28.9 & & & 3.5 & 5.3 & $\begin{array}{c}B C R-A B L 1 \\
\text { undetectable }\end{array}$ \\
\hline 9 & Y253F & Switch to dasatinib & 1 & & & 1.7 & 2.3 & MMR \\
\hline 10 & E275K, E459K & Switch to dasatinib & $2.7,2.7$ & & & 1.6 & 9 & MMR \\
\hline 11 & M351T & Switch to dasatinib & 2.4 & & & 7.5 & 10.9 & CCyR \\
\hline 12 & F359V & Switch to dasatinib & 2.4 & & & 2.2 & 9.8 & $\begin{array}{c}\text { BCR-ABL1 } \\
\text { undetectable }\end{array}$ \\
\hline 13 & M351T & Switch to nilotinib & 2.1 & & & 5.2 & 11.9 & $\begin{array}{c}B C R-A B L 1 \\
\text { undetectable }\end{array}$ \\
\hline 14 & G250E, Y253H & $\begin{array}{l}\text { Switch to nilotinib } \\
\text { (G250E)/switch to } \\
\text { dasatinib (Y253H) }\end{array}$ & $0.9,1.9$ & & & 1.2 & 2.9 & $\begin{array}{c}\text { BCR-ABL1 } \\
\text { undetectable } \\
\text { on dasatinib }\end{array}$ \\
\hline 15 & E459K & Switch to nilotinib & 4.4 & & & 1.7 & 3.7 & $\begin{array}{c}\text { BCR-ABL1 } \\
\text { undetectable }\end{array}$ \\
\hline 16 & F359V & Autologous HSCT & 1.1 & F359V & Stopping dasatinib & 4.8 & 11.4 & $\begin{array}{c}\text { BCR-ABL1 } \\
\text { undetectable } \\
\text { on bosutinib }\end{array}$ \\
\hline 17 & $\begin{array}{l}\text { Y253H, M351T, } \\
\text { F359V, E355G }\end{array}$ & Switch to dasatinib & $\begin{array}{c}0.9,2.3,2.3 \\
4.9\end{array}$ & F359V & Switch to nilotinib & 5.5 & 9.5 & $\begin{array}{l}\text { Lost major } \\
\text { CyR }^{\mathrm{a}}\end{array}$ \\
\hline 18 & Y253H & Switch to dasatinib & 20.2 & $\mathrm{Y} 253 \mathrm{H}$ & Switch to nilotinib & 1.9 & 9.8 & $\begin{array}{l}\text { Death due to } \\
\text { CML } \\
\text { (2 months } \\
\text { after last } \\
\text { sample } \\
\text { collected) }\end{array}$ \\
\hline 19 & F359V & Stopping imatinib & 7.8 & F359V & Switch to nilotinib & 4.4 & 9.5 & $\begin{array}{l}\text { Death due to } \\
\text { CML } \\
\text { (1 month after } \\
\text { last sample } \\
\text { collected) }\end{array}$ \\
\hline 20 & F359V, Q252H & Allogeneic HSCT & $15.4,15.4$ & F359V & Switch to nilotinib & 1.6 & 3.3 & $\begin{array}{l}\text { Death due to } \\
\text { CML (1.5 } \\
\text { months after } \\
\text { last sample } \\
\text { collected) }\end{array}$ \\
\hline 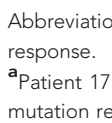 & $\mathrm{L}=$ chronic $\mathrm{mye}$ & $\begin{array}{l}\text { kaemia; } C C y R= \\
\text { low-dose dasa } \\
\text { ib. }\end{array}$ & te cytog & response; & $\begin{array}{l}\text { togenetic resp } \\
\text { No samples }\end{array}$ & $\begin{array}{l}\mathrm{CT}=\text { haematopoietic ste } \\
\text { eived for mutation analy }\end{array}$ & $\begin{array}{l}\text { ant; } \mathrm{Ml} \\
\text { t knov }\end{array}$ & $\begin{array}{l}\text { major molecular } \\
\text { ether the F317L }\end{array}$ \\
\hline
\end{tabular}




\section{MATERIALS AND METHODS}

Patients included in this retrospective study were (1) molecularly monitored at our institution since the starting imatinib (400-800 mg daily), (2) chronic phase at imatinib start, and (3) had mutations detectable using direct Sanger sequencing (Sangersequencing) during imatinib therapy. We identified 50 such patients with mutations monitored longitudinally for $0.3-11.9$ years since the starting imatinib (median 3.2 years). The study was performed in accordance with the Declaration of Helsinki, and approvals were obtained from the relevant institutional review boards. $B C R-A B L 1$ transcript levels were assessed by RT-QPCR (Branford and Hughes 2006b) and mutation analysis was performed by Sanger-sequencing (Branford and Hughes 2006a; mutations detectable when mutant clones represent $10-20 \%$ of the total leukaemic population). Sensitive mass spectrometry-based mutation analysis (detection limit $\sim 0.2 \%$ mutant; Parker et al, 2011) was performed on selected samples as indicated.

\section{RESULTS}

Fifty patients were followed since the starting imatinib in chronic phase who acquired mutations detectable by Sanger-sequencing during imatinib therapy. Of these, 48 patients had additional molecular follow-up after their mutation(s) were first detected. Mutations became undetectable by Sanger-sequencing in 20 of the 48 patients (27 mutations), at a median of 2.4 months after changing therapy (range 1-29 months; Table 1). The disappearance of individual mutations was associated with increased imatinib dose (3 mutations), stopping imatinib (1), haematopoietic stem cell transplant (HSCT) (6), chemotherapy (1), switching to nilotinib (3), or switching to dasatinib (14). All mutations that became undetectable when the patient switched to nilotinib or dasatinib were those known to be sensitive to the inhibitor received (for example, F359V in a patient switched to dasatinib).

In 15 of the 20 patients whose mutations became undetectable by Sanger-sequencing after changing therapy, the mutations have not been detected by Sanger-sequencing again with $0.1-7.5$ years of follow-up since the mutations were last detected (median 1.7 years; Table 1, patients 1-15).

In the other 5 of 20 patients, the same mutations as those originally detected (identical nucleotide exchange) reappeared and became detectable by Sanger-sequencing between 1.7 and 5.5 years after last detection (median 4.4 years; Table 1, patients 16-20). Patient 16 (Figure 1) acquired the F359V mutation on imatinib, and subsequently received an autologous HSCT and the mutation became undetectable by Sanger-sequencing. F359V could be detected at low levels at relapse post-transplant by mass spectrometry alone, suggesting that the mutant clone had not been eradicated at that time. After relapse post-transplant, the patient was treated with dasatinib for 3 years and $B C R-A B L 1$ transcripts became undetectable. F359V remained undetectable by Sangersequencing and became undetectable by mass spectrometry. Dasatinib therapy was stopped owing to intolerance, and while the patient was off all TKI therapy F359V rapidly (within 1 week) reappeared and was detected by Sanger-sequencing (100\% mutant), having been undetectable by Sanger-sequencing for 4.9 years and sensitive mass spectrometry for 2.7 years. To our knowledge, the acquisition of $B C R-A B L 1$ mutations while CML patients are off TKI therapy has not been reported previously. This suggests that the original F359V-mutant $B C R-A B L 1$-positive clone detected in this patient persisted at very low levels, and was the predominant leukaemic clone when dasatinib therapy was stopped. Given that the in vitro sensitivity of F359V-mutated BCR-ABL1 to dasatinib is approximately two-fold less than that of unmutated $B C R-A B L 1$ (O'Hare et al, 2005), it is conceivable that the F359Vmutant $B C R-A B L 1$-positive clone was more resilient to the selective pressure of dasatinib therapy than the unmutated clone, and hence became the major leukaemic clone during this time.

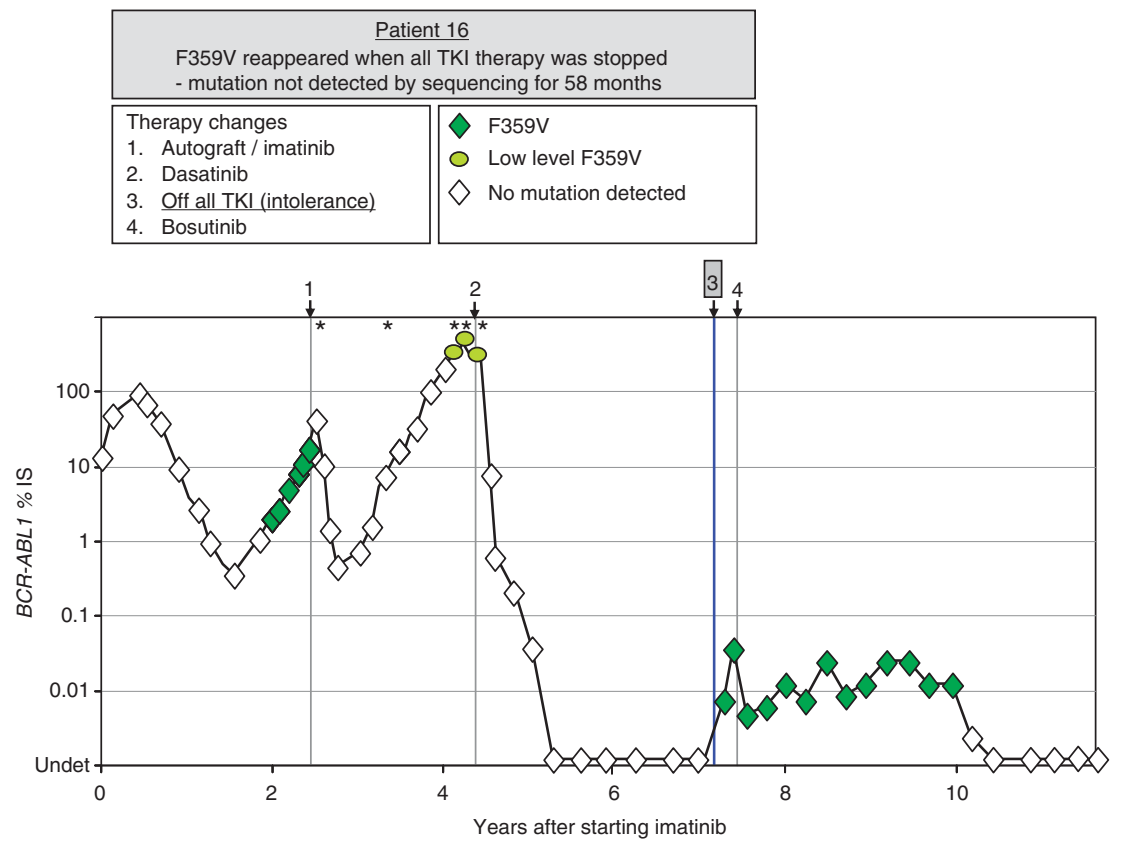

Figure 1. Longitudinal molecular analysis of a CML patient with an imatinib-resistant mutation that became undetectable by Sanger-sequencing after changing therapy, and then reappeared and was detected by Sanger-sequencing after stopping all TKI therapy. The graph plots BCR-ABL 1 transcript levels from the time of commencing imatinib. Shaded symbols indicate that a mutation was detected by Sanger-sequencing and/or mass spectrometry. Asterisks $\left({ }^{*}\right)$ indicate the time points when mass spectrometry mutation analysis was performed. Patient 16; 41 -year-old male, treated with IFN for 8 months before commencing imatinib in 2001. Before stopping all TKI therapy, the F359V mutation was not detectable by either mutation detection method. 

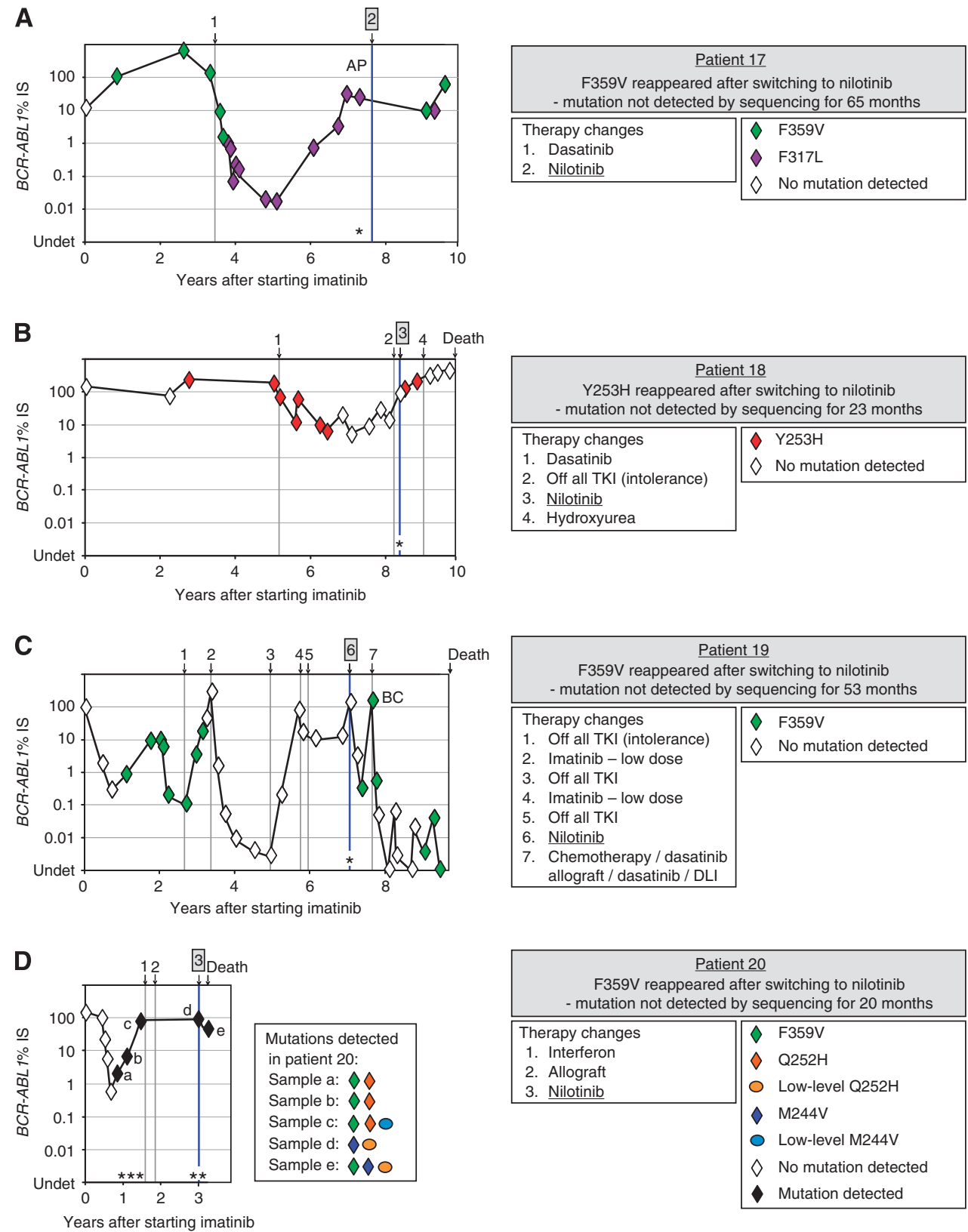

\begin{tabular}{|l|ll|}
\hline \multicolumn{2}{|c|}{$\begin{array}{c}\text { Patient } 20 \\
\text { F359V reappeared after switching to nilotinib } \\
\text { - mutation not detected by sequencing for 20 months }\end{array}$} \\
\hline \hline Therapy changes & $\diamond$ & F359V \\
1. Interferon & $\diamond$ & Q252H \\
2. Allograft & 0 & Low-level Q252H \\
3. Nilotinib & $\diamond$ & M244V \\
& 0 & Low-level M244V \\
& $\diamond$ & No mutation detected \\
& & Mutation detected \\
\hline
\end{tabular}

Figure 2. Longitudinal molecular analysis of four CML patients with imatinib- and nilotinib-resistant mutations that became undetectable by Sanger-sequencing after changing therapy, and then reappeared and were detected by Sanger-sequencing after switching to nilotinib and were associated with nilotinib resistance. The graphs plot BCR-ABL1 transcript levels from the time of commencing imatinib. Shaded symbols indicate that a mutation was detected by Sanger-sequencing and/or mass spectrometry. Asterisks $\left(^{\star}\right)$ indicate the time points when mass spectrometry mutation analysis was performed. (A) Patient 17; 57-year-old female, treated with hydroxyurea for 2.2 years before commencing imatinib in 2002; Abbreviation: AP, progression to accelerated phase. Before nilotinib therapy, the F359V mutation was not detectable by either mutation detection method. (B) Patient 18; 71-year-old female, treated with hydroxyurea for 17 months before commencing imatinib in 2001. Before nilotinib therapy, the $\mathrm{Y} 253 \mathrm{H}$ mutation was not detectable by either mutation detection method. (C) Patient 19; 35-year-old male, treated with IFN for 4 years before commencing imatinib in 2003; Abbreviations: DLI, donor leucocyte infusion; BC, progression to blast crisis. Before nilotinib therapy, the F359V mutation was not detectable by either mutation detection method. (D) Patient 20; 61-year-old male, treated with first-line imatinib in 2003. Before nilotinib therapy, the F359V mutation was not detectable by either mutation detection method. Owing to the complex mixture of mutations detected in patient 20, the samples assessed by Sanger-sequencing and mass spectrometry-based mutation analysis have been labelled (a-e), and the mutations detected at these time points are indicated in the adjacent box.

The original imatinib-resistant mutations in patients 17-20 (Figure 2) also confer resistance to nilotinib (Y253H and F359V), and their reappearance was associated with initiation of nilotinib therapy and subsequent nilotinib resistance. One of these four patients lost a major cytogenetic response (patient 17), and three died of their disease (patients 18-20). Mass spectrometry-based sensitive mutation analysis was performed on samples collected immediately before starting nilotinib to determine whether the mutations that subsequently reappeared could be detected at low levels. The mutations were below the level of mass spectrometry detection in all four patients at that time.

Patient 20 had additional evidence of selection, deselection, and persistence of mutations over time (Figure 2D). Sensitive mutation analysis was performed on all samples collected from this patient 
after mutations were first detected by Sanger-sequencing. On imatinib, F359V and Q252H were detected by Sanger-sequencing. Using mass spectrometry, low-level M244V could also be detected immediately before stopping imatinib. At the time of nilotinib commencement following relapse post-allogeneic HSCT, M244V was the only mutation detectable by Sanger-sequencing, and lowlevel Q252H was also detected by mass spectrometry. F359V became detectable by Sanger-sequencing after 1 month on nilotinib, and the patient subsequently died of their disease. This example demonstrates the complex dynamics of selection and deselection of mutant BCR-ABL1-positive clones that can occur in patients.

There was one other resistant mutation that had the potential to re-emerge on dasatinib therapy. Patient 6 acquired F317L and $\mathrm{Y} 253 \mathrm{H}$ on imatinib, which disappeared after increased imatinib dose (F317L) and switch to dasatinib (Y253H). After switching to dasatinib for 4 months, the patient rapidly achieved a major molecular response, which was followed by an allogeneic HSCT. Neither of the mutations was detected by Sanger-sequencing after they disappeared. The patient died of graft-versus-host disease.

\section{DISCUSSION}

We show that imatinib-resistant $B C R-A B L 1$ mutations that became undetectable by Sanger-sequencing, and even by sensitive analysis, after changing therapy may persist at very low levels for many years and should be taken into consideration when selecting TKIs to avoid their re-emergence.

It is unknown whether the reappearance of the mutations in the five patients described is due to clonal expansion of pre-existing low-level mutants or a new occurrence of the same mutation. However, the fact that the identical imatinib- and nilotinibresistant mutation reappeared in patient 16 (Figure 1) without selection by either of these inhibitors, and immediately upon release from kinase inhibition by dasatinib, suggests that this was indeed the re-emergence of the original mutant clone that had been undetectable by Sanger-sequencing for almost 5 years. To assess the likelihood that the reappearance of the four identical $B C R$ $A B L 1$ mutations in patients $17-20$ ( $\mathrm{Y} 253 \mathrm{H} \mathrm{x} 1, \mathrm{~F} 359 \mathrm{~V} \mathrm{x} 3$ ) is because of a new occurrence of the same mutations under the selective pressure of nilotinib, we used the published relative frequencies of mutation acquisition (Branford et al, 2009; Hughes et al, 2009). We estimate that the probability of patients 17-20 acquiring their mutation on imatinib and then again independently on nilotinib is $1.5 \times 10^{-12}$ (based on the frequency of F359V or $\mathrm{Y} 253 \mathrm{H}$ in imatinib-treated patients with mutations, 0.07 and 0.064 , respectively (Branford et al, 2009); imatinib-resistant patients with baseline mutation(s) acquiring newly detectable mutation(s) on nilotinib, 0.31 (Hughes et al, 2009); and new F359V/C or Y253H in patients with newly detectable mutation(s) on nilotinib, 0.21 and 0.18 , respectively (Hughes et al, 2009)). Therefore, the likelihood is low that the reappearance of the identical mutations in all of these patients is due to a new occurrence. This agrees with several studies showing that leukaemic relapse is almost always due to reemergence or evolution of the founder clone (Mullighan et al, 2008; Ding et al, 2012; Egan et al, 2012; Parkin et al, 2013), exemplified by a study by Egan et al (2012) who demonstrated the shifting dominance of tumour clones during evolution of multiple myeloma to plasma cell leukaemia.

Despite the low probability that the mutations that reappeared in our patients were a new occurrence of the same mutations, several studies have demonstrated convergent evolution within distinct tumour sub-clones of individual patients (Schaub et al, 2010; Anderson et al, 2011). Convergent evolution, the independent acquisition of the same biological trait in unrelated lineages, implies co-operativity among somatically mutated genes. A recent study of $47 \mathrm{CML}$ patients who had $\geqslant 2 B C R-A B L 1$ mutations found that the mutations could be both components of compound mutant transcripts and present as single mutations using a cloning and Sanger-sequencing technique (Khorashad et al, 2013).

Irrespective of whether the $B C R-A B L 1$ mutations in the five patients described herein have re-emerged owing to reselection and clonal expansion of pre-existing, persistent 'dormant' clones or whether the identical mutations have arisen independently, our data suggest that selection of a TKI to which a patient has exhibited a previous pattern of kinase domain-dependent resistance is best avoided. This study also emphasises the importance of characterising mutations during TKI therapy and before drug cessation or change of therapy as mutations can be rapidly deselected, masking the presence of potentially resistant clones. Furthermore, our data suggest that even if a historical mutation is not detectable using sensitive mutation analysis, it is not a guarantee that is has been eradicated, and thus the potential for re-emergence still exists. Selection of an inhibitor for which the historical mutation is sensitive would be recommended to reduce the risk of resistance to subsequent TKIs.

\section{ACKNOWLEDGEMENTS}

The authors thank the patients, clinicians and study centre co-ordinators who contributed samples and follow-up data for this study, and the staff of the Leukaemia Unit, Department of Molecular Pathology, SA Pathology for their excellent technical support.

\section{CONFLICT OF INTEREST}

$\mathrm{SB}$ and $\mathrm{TH}$ receive research funding and honoraria from Novartis, Bristol-Myers Squibb and Ariad Pharmaceuticals. DY receives research funding from Novartis and Bristol-Myers Squibb. The remaining authors declare no conflict of interest.

\section{REFERENCES}

Anderson K, Lutz C, van Delft FW, Bateman CM, Guo Y, Colman SM, Kempski H, Moorman AV, Titley I, Swansbury J, Kearney L, Enver T, Greaves M (2011) Genetic variegation of clonal architecture and propagating cells in leukaemia. Nature 469: 356-361.

Branford S, Hughes T (2006a) Detection of BCR-ABL mutations and resistance to imatinib mesylate. In Myeloid Leukemia: Methods and Protocols, Methods in Molecular Medicine, Illand H, Hertzgerg M, Marlton P (eds) Vol. 125, pp 93-106. Totawa, Humana Press: New Jersey.

Branford S, Hughes T (2006b) Diagnosis and monitoring of chronic myeloid leukemia by qualitative and quantitative RT-PCR. In Myeloid Leukemia: Methods and Protocols, Methods in Molecular Medicine, Illand H, Hertzgerg M, Marlton P (eds) Vol. 125, pp 69-92. Humana Press: Totawa, New Jersey.

Branford S, Melo JV, Hughes TP (2009) Selecting optimal second-line tyrosine kinase inhibitor therapy for chronic myeloid leukemia patients after imatinib failure: does the BCR-ABL mutation status really matter? Blood 114: 5426-5435.

Ding L, Ley TJ, Larson DE, Miller CA, Koboldt DC, Welch JS, Ritchey JK, Young MA, Lamprecht T, McLellan MD, McMichael JF, Wallis JW, Lu C, Shen D, Harris CC, Dooling DJ, Fulton RS, Fulton LL, Chen K, Schmidt H, Kalicki-Veizer J, Magrini VJ, Cook L, McGrath SD, Vickery TL, Wendl MC, Heath S, Watson MA, Link DC, Tomasson MH, Shannon WD, Payton JE, Kulkarni S, Westervelt P, Walter MJ, Graubert TA, Mardis ER, Wilson RK, DiPersio JF (2012) Clonal evolution in relapsed acute myeloid leukaemia revealed by whole-genome sequencing. Nature 481: 506-510.

Egan JB, Shi CX, Tembe W, Christoforides A, Kurdoglu A, Sinari S, Middha S, Asmann Y, Schmidt J, Braggio E, Keats JJ, Fonseca R, Bergsagel PL, Craig DW, Carpten JD, Stewart AK (2012) Whole-genome sequencing of 
multiple myeloma from diagnosis to plasma cell leukemia reveals genomic initiating events, evolution, and clonal tides. Blood 120: 1060-1066.

Gruber FX, Ernst T, Porkka K, Engh RA, Mikkola I, Maier J, Lange T, Hochhaus A (2012) Dynamics of the emergence of dasatinib and nilotinib resistance in imatinib-resistant CML patients. Leukemia 26: 172-177.

Hanfstein B, Muller MC, Kreil S, Ernst T, Schenk T, Lorentz C, Schwindel U, Leitner A, Hehlmann R, Hochhaus A (2011) Dynamics of mutant BCRABL-positive clones after cessation of tyrosine kinase inhibitor therapy. Haematologica 96: 360-366.

Hughes T, Saglio G, Branford S, Soverini S, Kim D-W, Muller MC, Martinelli G, Cortes J, Beppu L, Gottardi E, Kim D, Erben P, Shou Y, Haque A, Gallagher N, Radich J, Hochhaus A (2009) Impact of baseline BCR-ABL mutations on response to nilotinib in patients with chronic myeloid leukemia in chronic phase. J Clin Oncol 27: 4204-4210.

Khorashad JS, Kelley TW, Szankasi P, Mason CC, Soverini S, Adrian LT, Eide CA, Zabriskie MS, Lange T, Estrada JC, Pomicter AD, Eiring AM, Kraft IL, Anderson DJ, Gu Z, Alikian M, Reid AG, Foroni L, Marin D, Druker BJ, O'Hare T, Deininger MW (2013) BCR-ABL1 compound mutations in tyrosine kinase inhibitor-resistant CML: frequency and clonal relationships. Blood 121: 489-498.

Mullighan CG, Phillips LA, Su X, Ma J, Miller CB, Shurtleff SA, Downing JR (2008) Genomic analysis of the clonal origins of relapsed acute lymphoblastic leukemia. Science 322: 1377-1380.
O’Hare T, Walters DK, Stoffregen EP, Jia T, Manley PW, Mestan J, CowanJacob SW, Lee FY, Heinrich MC, Deininger MW, Druker BJ (2005) In vitro activity of Bcr-Abl inhibitors AMN107 and BMS-354825 against clinically relevant imatinib-resistant Abl kinase domain mutants. Cancer Res 65: 4500-4505.

Parker WT, Lawrence RM, Ho M, Irwin DL, Scott HS, Hughes TP, Branford S (2011) Sensitive detection of BCR-ABL1 mutations in patients with chronic myeloid leukemia after imatinib resistance is predictive of outcome during subsequent therapy. J Clin Oncol 29: $4250-4259$.

Parkin B, Ouillette P, Li Y, Keller J, Lam C, Roulston D, Li C, Shedden K, Malek SN (2013) Clonal evolution and devolution after chemotherapy in adult acute myelogenous leukemia. Blood 121: 369-377.

Schaub FX, Looser R, Li S, Hao-Shen H, Lehmann T, Tichelli A, Skoda RC (2010) Clonal analysis of TET2 and JAK2 mutations suggests that TET2 can be a late event in the progression of myeloproliferative neoplasms. Blood 115: 2003-2007.

Soverini S, Hochhaus A, Nicolini FE, Gruber F, Lange T, Saglio G, Pane F, Muller MC, Ernst T, Rosti G, Porkka K, Baccarani M, Cross NC, Martinelli G (2011) BCR-ABL kinase domain mutation analysis in chronic myeloid leukemia patients treated with tyrosine kinase inhibitors: recommendations from an expert panel on behalf of European LeukemiaNet. Blood 118: 1208-1215. 